Article

\title{
Phylogenetic Analysis and Molecular Diversity of Capsicum Based on rDNA-ITS Region
}

\author{
Kumpei Shiragaki ${ }^{1}$, Shuji Yokoi ${ }^{1,2,3}$ and Takahiro Tezuka ${ }^{1,2, *(1)}$ \\ 1 Department of Applied Life Sciences, Graduate School of Life and Environmental Sciences, Osaka Prefecture \\ University, Sakai, Osaka 599-8531, Japan; ma201027@edu.osakafu-u.ac.jp (K.S.); \\ shyokoi@plant.osakafu-u.ac.jp (S.Y.) \\ 2 Education and Research Field, College of Life, Environment, and Advanced Sciences, Osaka Prefecture \\ University, Sakai, Osaka 599-8531, Japan \\ 3 Bioeconomy Research Institute, Research Center for the 21st Century, Osaka Prefecture University, \\ Osaka 599-8531, Japan \\ * Correspondence: tezuka@plant.osakafu-u.ac.jp; Tel.: +81-72-254-8457
}

Received: 16 October 2020; Accepted: 18 November 2020; Published: 20 November 2020

\begin{abstract}
The genus Capsicum is comprised of 5 domesticated and more than 30 wild species. The region of nuclear ribosomal DNA internal transcribed spacers (rDNA-ITS) has widely been used for species identification, but has rarely been used in Capsicum. In this study, the evaluation of genetic diversity and a phylogenetic analysis were conducted using rDNA-ITS of 28 Capsicum accessions, including five domesticated and two wild species. We surveyed six conventional keys of domesticated species and another five traits in Capsicum accessions. Specific morphological characteristics were found in C. annuum, C. baccatum, and C. pubescens. Three subclones of each accession were sequenced, and rDNA-ITS polymorphisms were detected in all accessions excluding $C$. annuum, suggesting that incomplete concerted evolution occurred in rDNA-ITS of Capsicum. The genetic diversity was evaluated using nucleotide polymorphism and diversity. C. annuum had the lowest genetic diversity of all species in this study. The phylogenetic tree formed a species-specific clade for $C$. annuum, C. baccatum, and C. pubescens. The $C$. chinense clade existed in the $C$. frutescens clade, implying that it was a cultivated variant of $C$. frutescens. $C$. chacoense likely belonged to the $C$. baccatum complex according to its morphologic and genetic features. This study indicated that the rDNA-ITS region can be used for simple identification of domesticated Capsicum species.
\end{abstract}

Keywords: Capsicum; rDNA-ITS; phylogeny; genetic diversity; morphological traits

\section{Introduction}

The genus Capsicum has been cultivated since at least 6000 B.C. by Native Americans [1], and is now produced at over 40 million tons per year worldwide [2]. Fruits of the genus have good health properties such as stress relief and fat breakdown [3,4]. Capsaicin, which is the main pungent component of Capsicum, has attracted much attention because of beneficial health properties [3,5].

The genus has five domesticated species, C. annuum, C. baccatum, C. chinense, C. frutescens, and C. pubescens, and more than thirty wild species [6,7]. The origin of the Capsicum genus is postulated to be along the Andes of western to north-western South America [8]. The most commonly cultivated Capsicum species is C. annuum, which is domesticated in northern Latin America $[9,10]$. C. chinense and C. frutescens are domesticated in tropical northern Amazonia, while C. baccatum and C. pubescens are more prevalent in Latin America and mid-elevation southern Andes, respectively [9]. The domesticated species can be classified by morphological traits: seed color, corolla yellow spot, number of flowers per axil, calyx annular constriction, and flower position [11]. 
There are three genetic complexes based on the degree of genetic proximity and cross compatibility among the five domesticated species and closely related wild species. The complexes are the C. annuиm complex (C. annuum, C. chinense, and C. frutescens), C. baccatum complex (C. baccatum, C. praetermissum, and C. tovarii), and C. pubescens complex (C. pubescens, C. cardenasii, and C.eximium) [12-14]. Additionally, C. chacoense is sometimes assigned to the C. annuum complex [15] or C. baccatum complex [8] depending on the phylogenic analysis method.

In recent years, phylogenetic studies have been conducted to elucidate the relationship between Capsicum species based on molecular markers, including isozyme [16], random amplified polymorphic DNA [15], amplified fragment length polymorphism [17], simple sequence repeat [18,19], and single nucleotide polymorphism [20]. These studies analyzed the relationships between cultivated species, and indicated the species-specific clades formed; the species belonging to the $C$. annuum complex were genetically close to each other in phylogenetic trees.

DNA sequencing of genes or specific regions is often performed in phylogenetic studies. The internal transcribed spacers from nuclear ribosomal DNA (rDNA-ITS) is the most commonly used region for DNA barcoding [21]. For plant DNA barcoding, $r b c L$, $p s b A$-trnH spacer regions, and matK on plastid DNA are proposed in addition to rDNA-ITS [21]. In the phylogenic analysis of Capsicum species, the $p s b A$-trnH spacer region and matK on plastid DNA, and the partial sequence of waxy on nuclear DNA have been used for DNA barcoding [8]. On the other hand, rDNA-ITS has been used for the Capsicum species identification of 'Bhut Jolokia' [22] and genetic diversity evaluation [23,24]. Besides, it has been used for phylogenetic analysis of Capsicum species, although it is unclear whether rDNA-ITS can be used for the identification of domesticated Capsicum species, as the number of lines surveyed was one for most species surveyed [25].

The objectives of this study were to conduct phylogenetic analyses of Capsicum species using rDNA-ITS, verify whether rDNA-ITS can identify Capsicum species, especially domesticated ones, and describe their morphological characteristics. The rDNA-ITS sequences and morphological traits of domesticated and wild Capsicum species were examined. Moreover, genetic diversity within species was evaluated using rDNA-ITS sequences.

\section{Materials and Methods}

\subsection{Plant Materials}

Twenty-six Capsicum accessions, including five domesticated and two wild species, were provided by the National Agriculture and Food Research Organization Genebank (Tsukuba, Japan) or the USDA/ARS Capsicum germplasm collection (Griffin, GA, USA) (Table 1). After seeds were germinated on moistened filter papers in petri dishes, all seedlings were transplanted to pots $(9 \mathrm{~cm}$ diameter, $10 \mathrm{~cm}$ depth) filled with culture soil (Sakata Super Mix A, Sakata Seed Co., Yokohama, Japan). The seedlings were cultivated in constant conditions $\left(25^{\circ} \mathrm{C}, 12 / 12 \mathrm{~h}\right.$ light/dark, $\left.85 \mu \mathrm{mol} \mathrm{m}^{-2} \mathrm{~s}^{-1}\right)$. At 30 days after germination, plants were transferred to bigger pots $(21 \mathrm{~cm}$ diameter, $15 \mathrm{~cm}$ depth) and placed in a greenhouse (natural day length; Osaka Prefecture University, Sakai, Osaka, Japan). Only C. pubescens was kept at room temperature because it is not suitable for cultivation at a high temperature.

For morphologic investigations, five key traits (seed color, corolla yellow spot, number of flowers per axil, calyx annular constriction, and flower position) were described for the classification of domesticated Capsicum species according to the International Board for Plant Genetic Resources [11], in addition to other five traits (plant growth habit, anther color, calyx margin, fruit shape, and fruit pungency) (Figures 1 and 2). Morphologic surveys, excluding plant growth habit, seed color, fruit shape, and pungency, were conducted when each plant flowered. Plant growth habits were evaluated 5 months after germination when plant growth habits no longer change. Seed color was evaluated before sowing, and fruit shape and pungency were evaluated when each plant's fruits ripened. Fruit shapes were visually classified based on the illustration described by the International Plant Genetic Resources Institute (IPGRI) [26]. Fruit pungency was evaluated as presence or absence of pungency by 
sensory test. Three plants per accession were investigated to determine each trait and whether the traits were uniform within each accession.

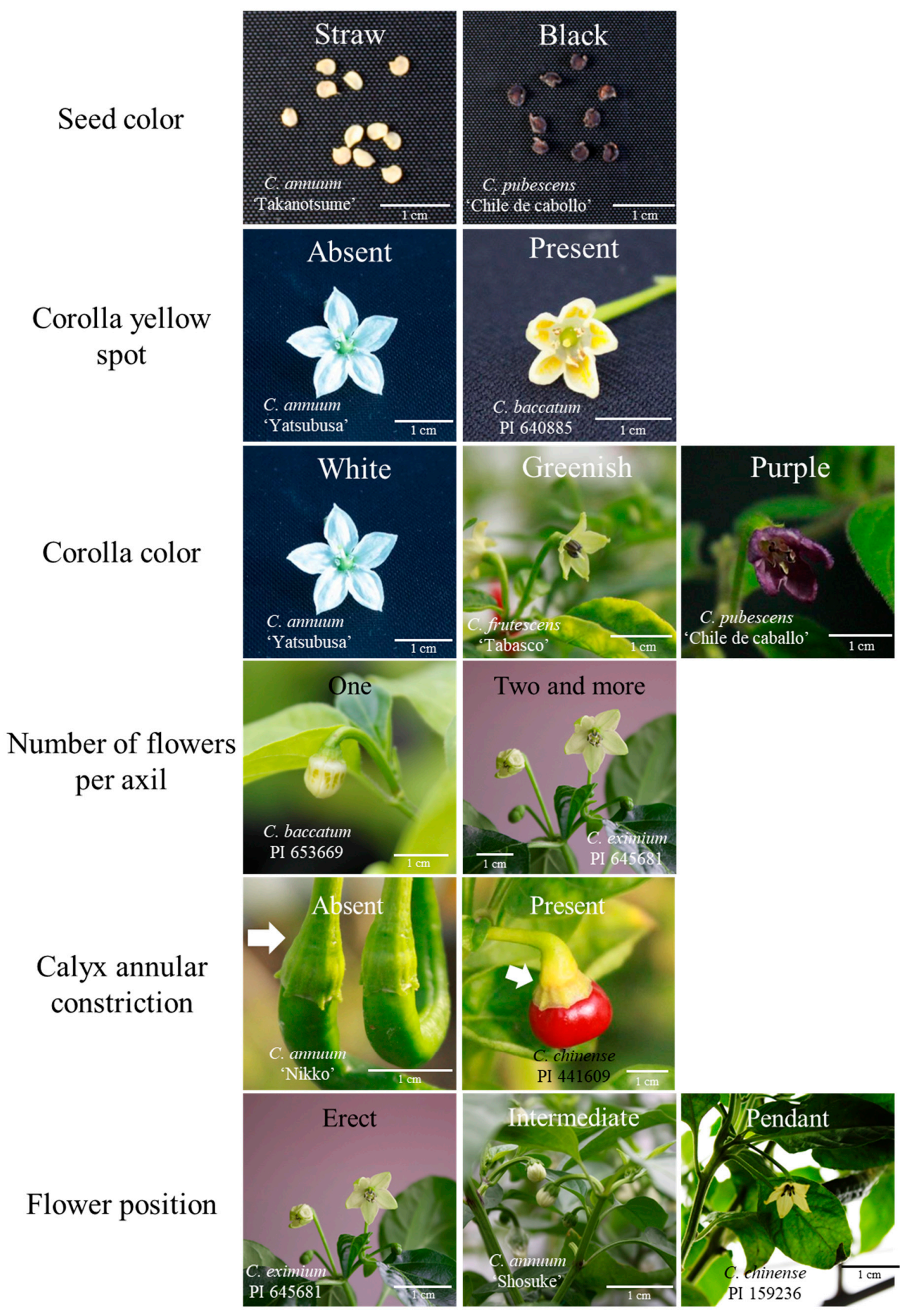

Figure 1. Traits for classification of domesticated species. 


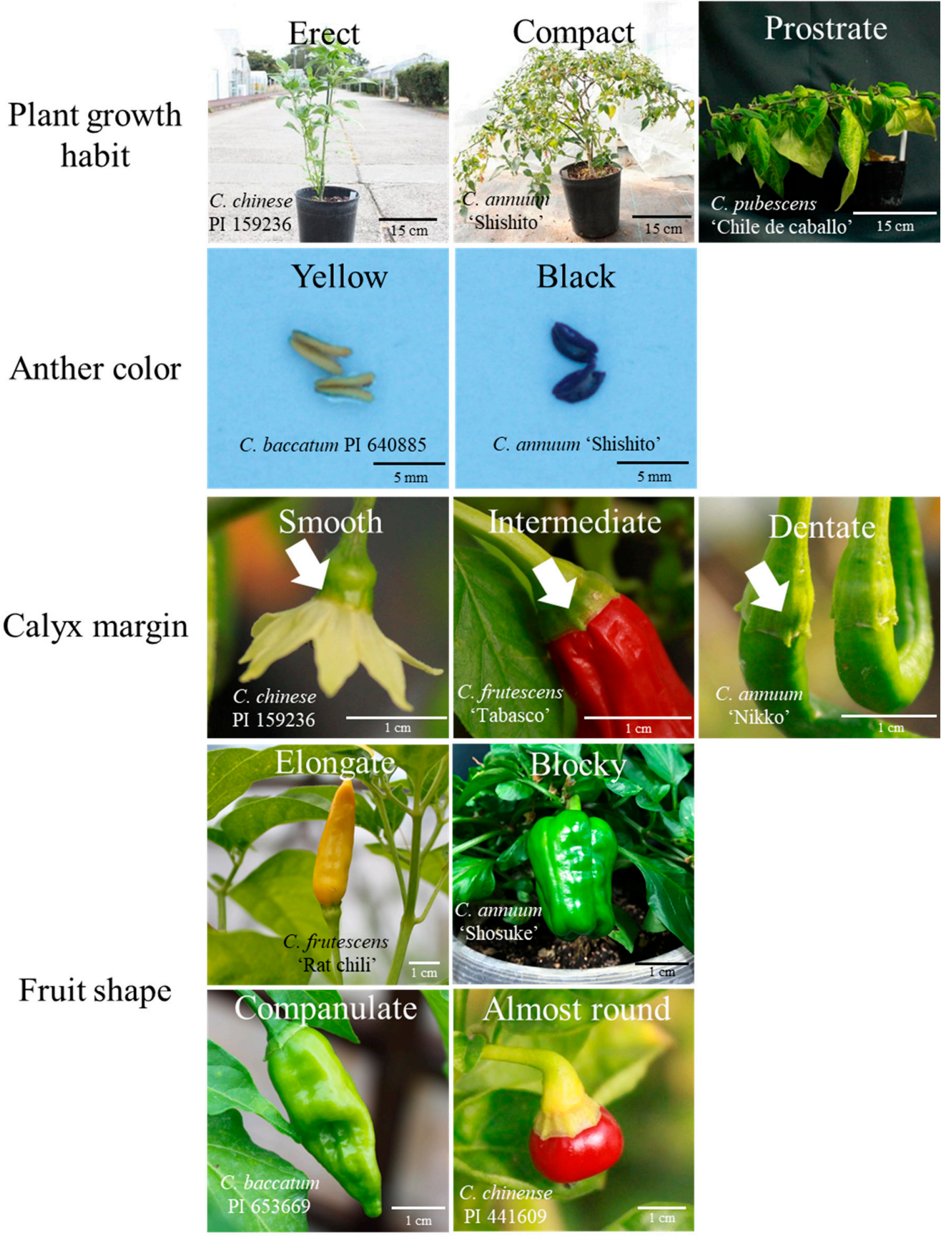

Figure 2. Other traits surveyed in this study. 
Table 1. Capsicum and rDNA-ITS accessions used in this study.

\begin{tabular}{|c|c|c|c|c|c|c|}
\hline Species & Accession No. & $\begin{array}{c}\text { Cultivar and Line } \\
\text { Name }\end{array}$ & Origin & Sources & $\begin{array}{c}\text { rDNA-ITS } \\
\text { Accession No. }\end{array}$ & $\begin{array}{l}\text { Reference of } \\
\text { rDNA-ITS }\end{array}$ \\
\hline \multirow[t]{11}{*}{ C. annuum } & JP 32511 & $\begin{array}{l}\text { Sapporo Onaga } \\
\text { Nanban }\end{array}$ & Japan & $\mathrm{NARO}^{\mathrm{a}}$ & LC510550 & This study \\
\hline & JP 32520 & Mie Midori & Japan & $\mathrm{NARO}^{\mathrm{a}}$ & LC510551 & This study \\
\hline & JP 32523 & Akashi & Japan & $\mathrm{NARO}^{\mathrm{a}}$ & LC510552 & This study \\
\hline & JP 32549 & Yatsubusa & Japan & NARO $^{a}$ & LC510553 & This study \\
\hline & JP 32555 & Zairai & Japan & $\mathrm{NARO}^{\mathrm{a}}$ & LC510554 & This study \\
\hline & JP 32562 & Nikko & Japan & $\mathrm{NARO}^{\mathrm{a}}$ & LC510555 & This study \\
\hline & JP 32566 & Fushimiamanaga & Japan & $\mathrm{NARO}^{\mathrm{a}}$ & LC510556 & This study \\
\hline & JP 82498 & Takanotsume & Japan & $\mathrm{NARO}^{\mathrm{a}}$ & LC510557 & This study \\
\hline & JP 123787 & Shosuke & Japan & $\mathrm{NARO}^{\mathrm{a}}$ & LC510558 & This study \\
\hline & JP 124339 & Murasaki & Japan & $\mathrm{NARO}^{\mathrm{a}}$ & LC510559 & This study \\
\hline & PI 640723 & Shishito & Japan & $\mathrm{NARO}^{\mathrm{a}}$ & LC510560 & This study \\
\hline \multirow[t]{4}{*}{ C. chinense } & PI 159236 & & USA & $\mathrm{USDA}^{\mathrm{b}}$ & LC510561-510563 & This study \\
\hline & PI 315008 & Scarlet Lantern & Peru & $\mathrm{USDA}^{\mathrm{b}}$ & LC510564-510566 & This study \\
\hline & PI 438614 & Habanero & Mexico & $\mathrm{USDA}^{\mathrm{b}}$ & LC510567-510568 & This study \\
\hline & PI 441609 & & Brazil & USDA $^{b}$ & LC510569-510570 & This study \\
\hline \multirow[t]{3}{*}{ C. frutescens } & PI 439512 & Rat chili & Mexico & $\mathrm{USDA}^{\mathrm{b}}$ & LC510571-510573 & This study \\
\hline & PI 586675 & Tabasco & USA & USDA $^{b}$ & LC510574-510576 & This study \\
\hline & PI 634826 & Greenleaf Tabasco & USA & USDA $^{b}$ & LC510577-510579 & This study \\
\hline \multirow[t]{3}{*}{ C. baccatum } & PI 640882 & & Peru & $\mathrm{USDA}^{\mathrm{b}}$ & LC510580-510582 & This study \\
\hline & PI 640885 & & India & USDA $^{b}$ & LC510583-510585 & This study \\
\hline & PI 653669 & & Colombia & USDA $^{b}$ & LC510586-510588 & This study \\
\hline \multirow[t]{3}{*}{ C. pubescens } & PI 593624 & Chile de caballo & Guatemala & USDA $^{b}$ & LC510589-510591 & This study \\
\hline & Grif 1613 & & Unknown & $\mathrm{USDA}^{\mathrm{b}}$ & LC510592-510594 & This study \\
\hline & Grif 1614 & & Mexico & USDA $^{b}$ & LC510595-510597 & This study \\
\hline C. chacoense & PI 273419 & & Argentina & USDA $^{b}$ & LC510598-510600 & This study \\
\hline C. eximium & PI 645681 & & $\begin{array}{l}\text { Australia } \\
\text { Mexico }\end{array}$ & USDA $^{b}$ & $\begin{array}{c}\text { LC510601-510603 } \\
\text { AY665841 }\end{array}$ & This study \\
\hline C. lycianthoides & & & USA & & DQ314158 & [28] \\
\hline $\begin{array}{l}\text { Solanum } \\
\text { nigrum }\end{array}$ & & & China & & FJ980391 & [29] \\
\hline
\end{tabular}

a National Agriculture and Food Research Organization Genebank (Tsukuba, Japan), b USDA/ARS Capsicum germplasm collection (Griffin, GA, USA).

\subsection{DNA Sequence of $r D N A-I T S$ Region}

Total DNA was extracted from individual leaves using the cetyltrimethylammonium bromide (CTAB) method [30] with minor modifications. Each leaf was ground in a mortar with liquid nitrogen. The ground leaf was mixed with CTAB isolation buffer $(2 \% \mathrm{w} / \mathrm{v} \mathrm{CTAB}, 1.4 \mathrm{M} \mathrm{NaCl}, 0.2 \%$ $\mathrm{v} / \mathrm{v} \beta$-mercaptoethanol, $20 \mathrm{mM}$ ethylenediaminetetraacetic acid (EDTA), $100 \mathrm{mM}$ Tris-HCl, $\mathrm{pH}$ 8.0) preheated at $60{ }^{\circ} \mathrm{C}$, and the mixture was incubated at $60{ }^{\circ} \mathrm{C}$ for $60 \mathrm{~min}$. The suspension was extracted twice with chloroform/isoamyl alcohol (24:1) and centrifuged for $15 \mathrm{~min}$ at $500 \mathrm{~g}$. The aqueous phase was transferred to a new tube; nucleic acids were precipitated by the addition of isopropanol ( $2 / 3$ volume) and centrifuged for $20 \mathrm{~min}$ at 1,000 g. The pellet was washed with $70 \%$ ethanol and dissolved in $40 \mu \mathrm{L}$ of Tris-EDTA (TE) buffer (10 mM Tris-HCl, 1 mM EDTA, pH 8.0).

To enhance the specificity, the rDNA-ITS region was amplified by touchdown PCR using forward primer (5'-CTGCGGAAGGATCATTGTCG-3') and reverse primer (5'-TAAACTCAGCGGGTAATCCC-3'), which were designed for Capsicum [31]. Touchdown PCR was performed in $40 \mu \mathrm{L}$ reaction mixture containing $0.2 \mathrm{mM}$ of dNTP, $0.2 \mu \mathrm{M}$ primers, $1 \mathrm{U}$ of KAPATaq EXtra DNA Polymerase (Kapa Biosystems Inc., Wilmington, MA, USA), 5×KAPATaq EXtra Buffer, and approximately $50 \mathrm{ng}$ of DNA as template. The first step started with $94{ }^{\circ} \mathrm{C}$ for $3 \mathrm{~min}$, followed by the touchdown phase, and PCR phase. The touchdown phase started with $94^{\circ} \mathrm{C}$ for $30 \mathrm{~s}$, annealing for $50 \mathrm{~s}$, followed by elongation at $68^{\circ} \mathrm{C}$ for $15 \mathrm{~s}$. The annealing step of the touchdown phase had a temperature ramp from 67 to $64{ }^{\circ} \mathrm{C}$ in seven cycles $\left(0.5^{\circ} \mathrm{C}\right.$ per cycle). The PCR phase had 33 thermal cycles, and each cycle had melting at $94{ }^{\circ} \mathrm{C}$ for $30 \mathrm{~s}$, annealing at $64^{\circ} \mathrm{C}$ for $50 \mathrm{~s}$, and elongation at $72{ }^{\circ} \mathrm{C}$ for $15 \mathrm{~s}$. The amplicons were verified on a $2 \%$ agarose gel in single band pattern. The amplicons were purified with Plus Gel Elution Kit (GMbiolab Co., Ltd., Taichung, Taiwan) following the manufacturer's protocol. 
The preliminary attempt to use direct nucleotide sequencing for rDNA-ITS amplicons frequently failed to obtain good electropherograms, suggesting the possibility that each band contained different sequences derived from rDNA-ITS paralogs within individuals. Therefore, PCR products were cloned using the pGEM $^{\circledR}$-T Easy Vector System I cloning kit (Promega Co. Ltd., Madison, WI, USA) with competent cells of Escherichia coli strain DH5 $\alpha$. The sequences of three cloned amplicons from one plant per Capsicum accession were determined using BigDye Terminator (version 3.1) cycle sequencing kit (Applied Biosystems Co. Ltd., Waltham, MA, USA), M13 forward (5'-GTAAAACGACGGCCAGT-3') and reverse (5'-CAGGAAACAGCTATGAC-3') primers, and an ABI PRISM 3130xl genetic analyzer (Applied Biosystems). Nucleotide sequences of rDNA-ITS determined are available in DDBJ/EMBL/GenBank (accession No. LC510550- 510603).

\subsection{Sequence Alignment and Phylogenetic Analysis}

The obtained rDNA-ITS sequences were aligned, using MUSCLE in the MEGA6 program [32], with other rDNA-ITS sequences downloaded from GenBank, including three sequences from C. eximium, C. lycianthoides, and Solanum nigrum (Table 1). The sequence of S. nigrum was used as the outgroup. The evolutionary history was inferred using MEGA6, with the maximum-likelihood method based on the general time reversible model [33]. Branch support was assessed by bootstrap resampling with 1000 replications.

\subsection{Evaluation of Genetic Diversity}

Based on the rDNA-ITS sequences, the number of nucleotide mutations, haplotype number and diversity, average number of nucleotide differences within population, and nucleotide polymorphism $(\theta w)$ and diversity $(\pi)$ were calculated using the DnaSP package ver. 6.0 [34].

\section{Results}

\subsection{Morphology Characters of Each Capsicum Species}

The morphological traits of 26 Capsicum accessions, including 11 C. annuum, 4 C. chinense, 3 C. frutescens, 3 C. baccatum, 1 C. pubescens, 1 C. chacoense, and 1 C. exmium, were studied (Table 1 , Supplemental Table S1). In addition to six key traits used for domesticated species classification, five traits were also surveyed (Figures 1 and 2, Table S1). The results showed that seed color was black in C. pubescens, while straw in others. The corolla color was yellow in C. baccatum, white or purple in C. annuum, white or greenish in C. chinense, greenish in C. frutescens and C. eximium, purple in C. pubescens, and white in C. baccatum and C. chacoense. Some accessions in C. annuum and C. chinense had two or more flowers per axil, whereas others only had one. Two out of four $C$. chinense accessions had calyx annular constriction. Flower position was erect in C. frutescens, C. chacoense, and C. eximium, erect or intermediate in $C$. annuиm, erect, intermediate, or pendant in C. chinense, intermediate or pendant in C. baccatum, and intermediate in C. pubescens. All accessions of five domesticated species had been correctly classified according to morphological traits. However, the $C$. eximium accession was likely to be misclassified because it is characterized by a purple corolla [35]; this misclassification was also inferred from the following phylogenetic analysis based on rDNA-ITS in the present study. The morphological traits of the $C$. chacoense accession were in line with those described in literature [36].

Plant growth habit was compact in C. annuum and C. baccatum, erect or compact in C. chinense, erect in C. frutescens and C. eximium, and prostrate in C. pubescens and C. chacoense. Anther color was yellow in C. baccatum and C. chacoense, while black in others. Calyx margin was dentate in C. annuum, C. pubescens and C. chacoense, smooth in C. chinense, and smooth or intermediate in C. frutescens and C. baccatum. Fruit shape was elongated or blocky in C. annuum, elongated, campanulate, or almost round in C. chinense, elongated in C. frutescens, C. eximium, and C. chacoense, elongated or campanulate in C. baccatum, and almost round in C. pubescens. Fruit pungency was present or absent in C. annuum, while present in others. 


\subsection{Variations of Sequence Length and GC Content, and Genetic Diversity in rDNA-ITS}

We obtained the rDNA-ITS sequences from three subclones for each of the 26 Capsicum accessions. In all accessions of $C$. annuum, each had the same sequence among three subclones. C. chinense 'Habanero' and PI 441609 had the same sequence in two of the three subclones. In other accessions, three subclones from the same individual were different from one another. Additionally, rDNA-ITS sequences of C. eximium, C. lycianthoides, and Solanum nigrum were obtained from the NCBI database. Lengths of ITS1 were from 140 to 245,138 to 161 for $5.8 \mathrm{~S}$ rDNA, and 200 to 233 for ITS2 (Table S2). The GC percentages of ITS1 were from $51.9 \%$ to $72.0 \%, 43.8 \%$ to $55.0 \%$ for $5.8 \mathrm{~S}$ rDNA, and $52.7 \%$ to $70.0 \%$ for ITS2 (Table S2).

The genetic diversity of rDNA-ITS in each species was evaluated (Table 2). In C. annuum, 7 of 11 sequences were the same haplotype, and 2 of the 10 sequences were the same haplotype in $C$. chinense, whereas sequences of other species were all different haplotypes. Therefore, haplotype diversity was lower in C. annuum and C. chinense than in others. We used two indicators of genetic diversity: nucleotide polymorphism $(\theta w)$ [37], which reflects the number of mutation nucleotides in a population, and nucleotide diversity $(\pi)$ [38], which reflects the average number of nucleotide differences between two sequences selected at random. The genetic diversity of rDNA-ITS in C. annuum was lowest among all species used in this study according to nucleotide polymorphism and diversity (Table 2).

\subsection{Phylogenetic Relationship Between Capsicum Species Based on rDNA-ITS}

We constructed a phylogenetic tree using the maximum-likelihood method based on the rDNA-ITS sequences (Figure 3, Figure S1). The phylogenetic tree showed that in-group species were divided into two clades (C. pubescens clade vs. the others) with 50\% support value (Figure 3 ). The $C$. annuum clade then formed a monophyletic group with $71 \%$ support value. In addition to the $C$. annuum clade and the $C$. pubescens clade, the phylogenetic tree formed the $C$. chinense and $C$. frutescens clade and the $C$. baccatum clade, although the bootstrap value was less than $50 \%$. The $C$. chinense clade was derived from the C. chinense and C. frutescens clade. C. eximium PI 645681 existed in the C. chinense and C. frutescens clade, while C. chacoense PI 273419 existed in the C. baccatum clade. 
Table 2. Evaluation of genetic diversity within species based on rDNA-ITS.

\begin{tabular}{|c|c|c|c|c|c|c|c|c|}
\hline Species & $\begin{array}{c}\text { Number of } \\
\text { Plant Materials }\end{array}$ & $\begin{array}{l}\text { Number of } \\
\text { Sequences }\end{array}$ & $\begin{array}{l}\text { Number of } \\
\text { Haplotypes }\end{array}$ & $\begin{array}{c}\text { Haplotype } \\
\text { Diversity }\end{array}$ & $\begin{array}{l}\text { Number of } \\
\text { Mutation } \\
\text { Nucleotides }\end{array}$ & $\begin{array}{c}\text { Nucleotide } \\
\text { Polymorphism } \\
(\theta w)\end{array}$ & $\begin{array}{l}\text { Average Number of } \\
\text { Nucleotide Differences }\end{array}$ & $\begin{array}{l}\text { Nucleotide } \\
\text { Diversity }(\pi)\end{array}$ \\
\hline C. annuum & 11 & 11 & 4 & 0.49091 & 9 & 0.00808 & 1.78182 & 0.00476 \\
\hline C. chinense & 4 & 10 & 9 & 0.95556 & 46 & 0.03661 & 14.55556 & 0.03239 \\
\hline C. frutescens & 3 & 9 & 9 & 1 & 150 & 0.13385 & 40.47222 & 0.09922 \\
\hline C. baccatum & 3 & 9 & 9 & 1 & 110 & 0.10795 & 34.11111 & 0.09187 \\
\hline C. pubescens & 3 & 9 & 9 & 1 & 74 & 0.06188 & 18.52778 & 0.04449 \\
\hline C. chacoense & 1 & 3 & 3 & 1 & 84 & n.d. & 56 & n.d. \\
\hline C. еximium & 1 & 3 & 3 & 1 & 49 & n.d. & 32.66667 & n.d. \\
\hline Total & 26 & 57 & 48 & 0.981 & 279 & 0.14439 & 34.323 & 0.08192 \\
\hline
\end{tabular}

${ }^{a}$ Number of sequences indicates the number of subclones, excluding overlapped subclones in each accession. "n.d." indicates that the calculations could not be performed due to insufficient numbers of sequences. 


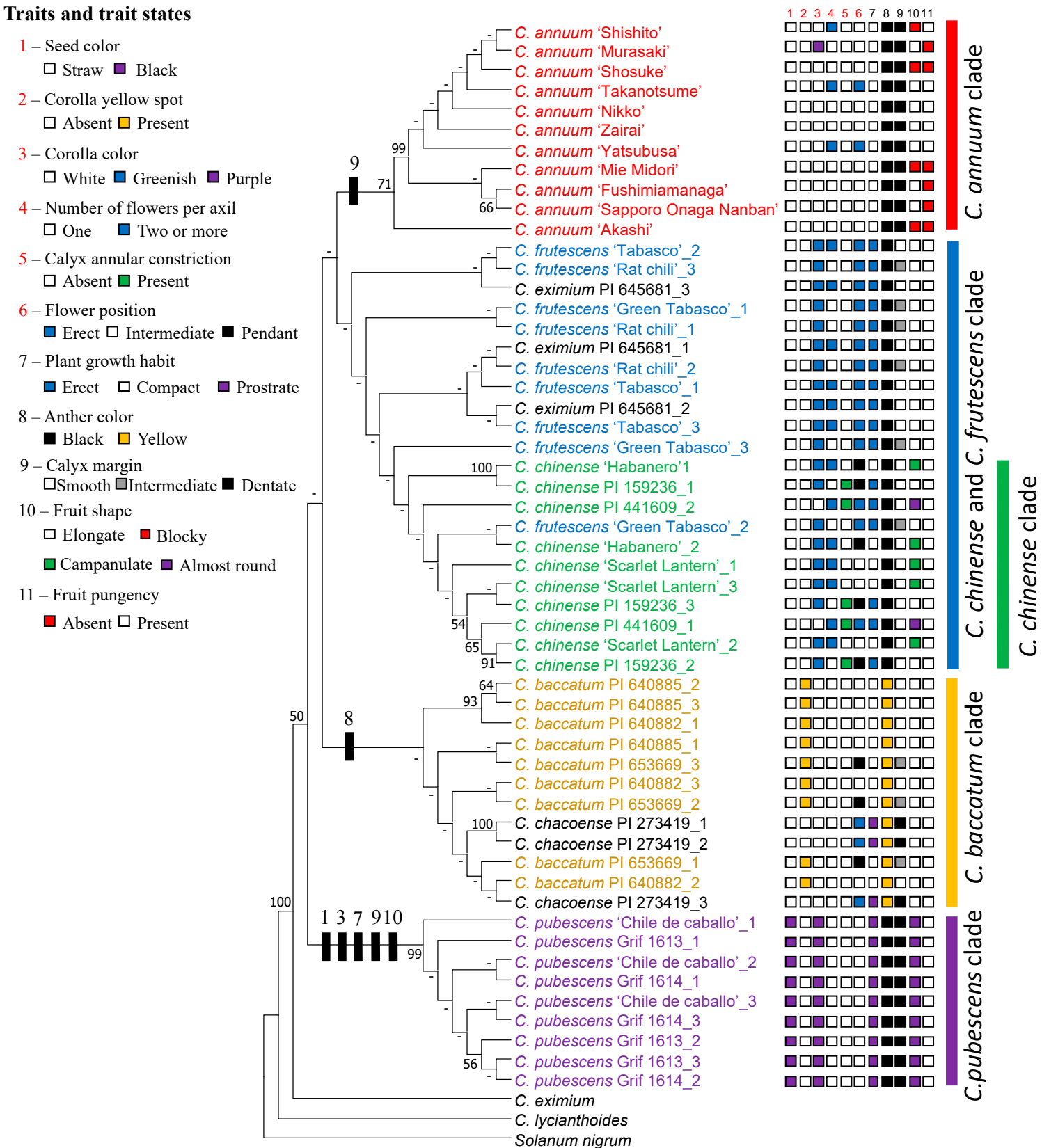

Figure 3. Molecular phylogenetic tree based on a maximum-likelihood analysis of rDNA ITS sequences, and evolution of morphological traits in Capsicum. Bootstrap $=1000$ replicates (any clade with a hyphen has a bootstrap <50). Trait state changes are indicated by black rectangles with the number of the trait on the phylogenetic tree. Traits 1 to 6 (written in red) are the key morphological traits of domesticated species.

\section{Discussion}

All accessions of five domesticated species had been correctly classified by key morphological characteristics for domesticated Capsicum species classification [11]. C. chacoense PI 273419 would be correctly classified because the morphological traits were not in conflict with those described in the literature [36]. However, C. eximium PI 645681 may be misclassified, because the corolla color of PI 645681 was greenish, while it is purple in general [35]. According to the key morphological characteristics of domesticated Capsicum species [11], C. eximium PI 645681 should be classified as C. frutescens. Although C. eximium PI 645681 belonged to the C. chinense and C. frutescens clade, the 
C. eximium (AY665841) obtained from NCBI did not belong to any clades in the phylogenetic tree on rDNA-ITS (Figure 3). The deviation of C. eximium (AY665841) in the tree seemed to reflect that C. eximium is not very close to domesticated Capsicum species [8]. Therefore, C. eximium PI 645681 seemed to be $C$. frutescens considering its morphological and molecular traits.

The rDNA-ITS is a tandem repeat unit of hundreds or thousands of copies [39]. Individual copies of rDNA-ITS are homogenized in the same sequence type via concerted evolution, which is thought to be induced by unequal crossing over and high frequency of gene conversion [40]. However, in this study, rDNA-ITS polymorphisms within individuals were detected in Capsicum species, except in C. annuum, suggesting that concerted evolution was incomplete. The polymorphism of rDNA-ITS paralogs within individuals is also observed in other plants [41,42]. Although the mechanism of incomplete concerted evolution has not been elucidated thoroughly, some reports have shown that it occurs in cases where hybridization is involved [43], or when paralogous rDNA-ITS sequences are present in a non-homologous locus [44]. Although further analysis is needed to determine the factors of incomplete concerted evolution, this study revealed that it occurs in rDNA-ITS of Capsicum, except for C. annuum.

The genetic diversity in Capsicum species was investigated using rDNA-ITS (Table 2). The results suggested that the genetic diversity in $C$. annuum was much lower than other Capsicum species. Moreover, the genetic differences between lines of $C$. annuum were small in the phylogenetic tree (Figure S1). Low diversity of $C$. annuum was also observed in the analysis of $C$. annuum lines worldwide using 746k polymorphic sites [45]. Only Japanese cultivars of the C. annuum accessions were used in this study. It is possible that the genetic diversity of $C$. annuum, especially in Japanese cultivars, has decreased due to factors like intensive selective breeding.

The phylogenetic tree based on rDNA-ITS formed the $C$. annuum clade, the $C$. chinense and $C$. frutescens clade, the $C$. baccatum clade, and the C. pubescens clade. Therefore, rDNA-ITS can distinguish domesticated Capsicum species, but this was difficult for C. chinense and C. frutescens (Figure 3). However, the clades supported by bootstrap values above $50 \%$ were just the $C$. annuum clade and the C. pubescens clade. Therefore, rDNA-ITS should be used only for a rough identification of domesticated Capsicum. The $C$. chinense clade might be divided into two groups: one consisting of mainly $C$. frutescens and another consisting of $C$. chinense, suggesting that $C$. chinense may have evolved from $C$. frutescens. Consequently, $C$. chinense may be a cultivated variant of $C$. frutescens [46]. It was unclear to which complex $C$. chacoense belongs $[8,15]$, but according to the phylogenetic tree based on rDNA-ITS, it belonged to the $C$. baccatum complex (Figure 3); it also had yellow anther, the same morphological trait as C. baccatum.

The phylogenetic analysis using rDNA-ITS almost agreed with previous studies using molecular markers [15,16,18-20] and DNA barcoding [8] with sequences except rDNA-ITS in terms of the formation of species clades and phylogenetic relations, although rDNA-ITS could not differentiate between $C$. chinense and $C$. frutescens. The analysis using molecular markers or DNA barcoding except rDNA-ITS requires many Capsicum species for species identification, and thus takes a lot of effort. On the other hand, many sequences of the rDNA-ITS region in Capsicum species have been accumulated in the NCBI database. Therefore, phylogenetic analysis using the rDNA-ITS region would be a low-effort method for Capsicum species identification.

The evolution of the morphological traits of each species on a phylogenetic tree was also studied (Figure 3). In the key morphological traits for domesticated species classification, black seed and purple corolla were the characteristic traits of the C. pubescens clade [46]. Most accessions in the $C$. chinense and C. frutescens clade had a greenish corolla (Figure 3, Table S1) [46,47], although it was not a characteristic trait of $C$. chinense and $C$. frutescens clades. In the traits not used for domesticated species classification, common traits were found in each clade. In the C. pubescens clade, prostrate growth habit and almost-round fruit were the characteristic traits [46]. A dentate margin of the calyx was a C. pubescens characteristic trait (Figure 3, Table S1), although a large-scale survey is needed to confirm that. The phylogenetic tree in Figure 3 suggested that yellow anther in the C. baccatum clade 
seemed to be a trait obtained after differentiating from a common ancestor of $C$. annuum, C. chinense, and $C$. frutescens. It was necessary to investigate the anther color of other species in the C. baccatum complex to verify yellow anther as the characteristic trait of the $C$. baccatum complex. C. tovarii and $C$. praetermissum, belonging to the $C$. baccatum complex, had blue and purple anthers, respectively $[13,48]$; therefore, yellow anther was not a characteristic trait of the C. baccatum complex, but it may be useful for the identification of some species belonging to the $C$. baccatum complex. In the C. annuum clade, dentate calyx margin was a trait distinct from the C. chinense and C. frutescens clades (Figure 3, Table S1). However, dentate calyx margin cannot be used as a characteristic trait because there were some lines in C. annuum that had smooth or intermediate calyx margin [49]. All C. frutescens accessions had erect flower position and growth habit, but these traits cannot distinguish $C$. frutescens from $C$. annuum and C. chinense (Figure 3, Table S1). No new traits were found to distinguish C. annuum, C. chinense, and C. frutescens through the key traits of domesticated species, but based on their morphological traits, they were closely related.

This study revealed the phylogenetic relationships between Capsicum species based on 11 morphological traits and rDNA-ITS sequences, and the low genetic diversity of $C$. annuum cultivars based on rDNA-ITS sequences. These results may be used for future studies on species differentiation and genetic resources in Capsicum.

Supplementary Materials: The following are available online at http://www.mdpi.com/2311-7524/6/4/87/s1, Figure S1: Molecular phylogenetic tree based on a maximum-likelihood analysis of rDNA-ITS sequences with evolutionary distances, Table S1: Morphological traits of Capsicum investigated in the present study, Table S2: Length range (bp) and GC content (\%) analysis of ITS sequences.

Author Contributions: Conceptualization, T.T.; methodology, T.T.; validation, K.S., S.Y., and T.T.; investigation, K.S.; data curation, K.S.; writing—original draft preparation, K.S.; writing—review and editing, K.S., S.Y., and T.T.; visualization, K.S.; supervision, S.Y.; project administration, T.T.; funding acquisition, T.T. All authors have read and agreed to the published version of the manuscript.

Funding: This research was funded by JSPS KAKENHI (Grant Number JP17K15224 and JP20K05988) from the Japan Society for the Promotion of Science.

Acknowledgments: We are grateful to the National Agriculture and Food Research Organization Genebank (Tsukuba, Japan) and the USDA/ARS Capsicum germplasm collection (Griffin, GA, USA) for providing Capsicum seeds.

Conflicts of Interest: The authors declare no conflict of interest.

\section{References}

1. Perry, L.; Dickau, R.; Zarrillo, S.; Holst, I.; Pearsall, D.M.; Piperno, D.R.; Berman, M.J.; Cooke, R.G.; Rademaker, K.; Ranere, A.J.; et al. Starch fossils and the domestication and dispersal of chili peppers (Capsicum spp. L.) in the Americas. Science 2007, 315, 986-988. [CrossRef] [PubMed]

2. FAO. Available online: http://faostat.fao.org/site/567/default.aspx\#ancor (accessed on 5 April 2020).

3. Kobayashi, A.; Osaka, T.; Namba, Y.; Inoue, S.; Lee, T.H.; Kimura, S. Capsaicin activates heat loss and heat production simultaneously and independently in rats. Am. J. Physiol. Regul. Integr. Comp. Physiol. 1998, 275, R92-R98. [CrossRef]

4. Bach, F.W.; Yaksh, T.L. Release of $\beta$-endorphin immunoreactivity into ventriculo-cisternal perfusate by lumbar intrathecal capsaicin in the rat. Brain Res. 1995, 701, 192-200. [CrossRef]

5. Watanabe, T.; Kawada, T.; Kato, T.; Harada, T.; Iwai, K. Effects of capsaicin analogs on adrenal catecholamine secretion in rats. Life Sci. 1994, 54, 369-374. [CrossRef]

6. Carrizo Garcia, C.; Sterpetti, M.; Volpi, P.; Ummarino, M.; Saccardo, F. Wild Capsicums: Identification and in situ analysis of Brazilian species. In Proceedings of the Breakthroughs in the Genetics and Breeding of Capsicum and Eggplant, Torino, Italy, 2-4 September 2013; pp. 205-213.

7. Heiser, C.B.; Pickersgill, B. Names for the cultivated Capsicum species (Solanaceae). Taxon 1969, 18, 277-283. [CrossRef]

8. Carrizo García, C.; Barfuss, M.H.J.; Sehr, E.M.; Barboza, G.E.; Samuel, R.; Moscone, E.A.; Ehrendorfer, F. Phylogenetic relationships, diversification and expansion of chili peppers (Capsicum, Solanaceae). Ann. Bot. 2016, 118, 35-51. [CrossRef] [PubMed] 
9. Pickersgill, B. Relationships between weedy and cultivated forms in some species of chili peppers (Genus Capsicum). Evolution 1971, 25, 683-691.

10. Kraft, K.H.; Brown, C.H.; Nabhan, G.P.; Luedeling, E.; Luna Ruiz, J.d.J.; Coppens d'Eeckenbrugge, G.; Hijmans, R.J.; Gepts, P. Multiple lines of evidence for the origin of domesticated chili pepper, Capsicum annuum in Mexico. Proc. Natl. Acad. Sci. USA 2014, 111, 6165-6170. [CrossRef]

11. IBPGR. Genetic Resources of Capsicum: A global Plan of Action; IBPGR Executive Secretariat: Rome, Italy, 1983.

12. Moscone, E.A.; Scaldaferro, M.A.; Grabiele, M.; Cecchini, N.M.; Sánchez García, Y.; Jarret, R.; Daviña, J.R.; Ducasse, D.A.; Barboza, G.E.; Ehrendorfer, F. The evolution of chili peppers (Capsicum-Solanaceae): A cytogenetic perspective. Acta Hortic. 2007, 745, 137-170. [CrossRef]

13. Tong, N.; Bosland, P.W. Capsicum tovarii, a new member of the Capsicum baccatum complex. Euphytica 1999, 109, 71-77. [CrossRef]

14. Pickersgill, B. The genus Capsicum-A multidisciplinary approach to the taxonomy of cultivated and wild plants. Biol. Zentralbl. 1988, 107, 381-389.

15. Ince, A.G.; Karaca, M.; Onus, A.N. Genetic relationships within and between Capsicum species. Biochem. Genet. 2010, 48, 83-95. [CrossRef] [PubMed]

16. McLeod, M.J.; Guttman, S.I.; Eshbaugh, W.H.; Rayle, R.E. An electrophoretic study of evolution in Capsicum (Solanaceae). Evolution 1983, 37, 562-574. [CrossRef] [PubMed]

17. Paran, I.; Aftergoot, E.; Shifriss, C. Variation in Capsicum annuum revealed by RAPD and AFLP markers. Euphytica 1998, 99, 167-173. [CrossRef]

18. Silvar, C.; García González, C.A. Deciphering genetic diversity in the origins of pepper (Capsicum spp.) and comparison with worldwide variability. Crop Sci. 2016, 56, 3100-3111. [CrossRef]

19. Nicolaï, M.; Cantet, M.; Lefebvre, V.; Sage-Palloix, A.M.; Palloix, A. Genotyping a large collection of pepper (Capsicum spp.) with SSR loci brings new evidence for the wild origin of cultivated C. annuum and the structuring of genetic diversity by human selection of cultivar types. Genet. Resour. Crop Evol. 2013, 60, 2375-2390. [CrossRef]

20. Jeong, H.J.; Jo, Y.D.; Park, S.W.; Kang, B.C. Identification of Capsicum species using SNP markers based on high resolution melting analysis. Genome 2010, 53, 1029-1040. [CrossRef]

21. Hollingsworth, P.M.; Graham, S.W.; Little, D.P. Choosing and using a plant DNA barcode. PLoS ONE 2011, 6, e19254. [CrossRef]

22. Purkayastha, J.; Alam, S.I.; Gogoi, H.K.; Singh, L.; Veer, V. Molecular characterization of 'Bhut Jolokia' the hottest chilli. J. Biosci. 2012, 37, 757-768. [CrossRef]

23. Sun, Y.L.; Choi, I.L.; Lee, Y.B.; Choi, K.Y.; Hong, S.K.; Kang, H.M. Molecular diversity and phylogentic analysis of Capsicum annuum varieties using the nrDNA ITS region. Sci. Hortic. 2014, 165, 336-343. [CrossRef]

24. Kehie, M.; Kumaria, S.; Devi, K.S.; Tandon, P. Genetic diversity and molecular evolution of Naga King Chili inferred from internal transcribed spacer sequence of nuclear ribosomal DNA. Meta Gene 2016, 7, 56-63. [CrossRef] [PubMed]

25. Xu, X.W.; Li, Y.; Wang, H.M.; Xu, X.; Li, T.; Luo, S. Analysis on the internal transcribed spacers (ITS) sequences and phylogenetic of pepper. Acta Hortic. Sin. 2014, 41, 881-888.

26. IPGRI; AVRDC. Descriptors for Capsicum (Capsicum spp.); International Plant Genetic Resources Institute: Washington, DC, USA, 1995; p. 100.

27. Whitson, M.; Manos, P.S. Untangling Physalis (Solanaceae) from the Physaloids: A two-gene phylogeny of the Physalinae. Syst. Bot. 2005, 30, 216-230. [CrossRef]

28. Smith, S.D.; Baum, D.A. Phylogenetics of the florally diverse Andean clade Iochrominae (Solanaceae). Am. J. Bot. 2006, 93, 1140-1153. [CrossRef] [PubMed]

29. Chen, S.L.; Han, J.P. Identification of medicinal plants using DNA barcoding technique. Wiley Online Libr. 2009, (unpublished).

30. Murray, M.G.; Thompson, W.F. Rapid isolation of high molecular weight plant DNA. Nucleic Acids Res. 1980, 8, 4321-4326. [CrossRef] [PubMed]

31. Sui, Y.H.; Hui, N.B. Acquisition, identification and analysis of an interspecific Capsicum hybrid (C. annuum $\times$ C. chinense). J. Hortic. Sci. Biotechnol. 2015, 90,31-38. [CrossRef]

32. Tamura, K.; Stecher, G.; Peterson, D.; Filipski, A.; Kumar, S. MEGA6: Molecular evolutionary genetics analysis version 6.0. Mol. Biol. Evol. 2013, 30, 2725-2729. [CrossRef]

33. Nei, M.; Kumar, S. Molecular Evolution and Phylogenetics; Oxford University Press: Oxford, UK, 2000. 
34. Rozas, J.; Ferrer-Mata, A.; Sánchez-DelBarrio, J.C.; Guirao-Rico, S.; Librado, P.; Ramos-Onsins, S.E.; Sánchez-Gracia, A. DnaSP 6: DNA sequence polymorphism analysis of large data sets. Mol. Biol. Evol. 2017, 34, 3299-3302. [CrossRef]

35. Eshbaugh, W.H. The taxonomy of the genus capsicum. In Peppers: Botany, Production and Uses; Russo, V.M., Ed.; CAB International: Oxford, MS, USA, 2012; pp. 14-28.

36. Hunziker, A.T. Estudios sobre Solanaceae, I. Sinopsis de las species silvestres de Capsicum de Argentina y Paraguay. Darwiniana 1950, 9, 225-247.

37. Watterson, G.A. On the number of segregating sites in genetical models without recombination. Theor. Popul. Biol. 1975, 7, 256-276. [CrossRef]

38. Nei, M. Estimation of average heterozygosity and genetic distance from a small number of individuals. Genetics 1978, 89, 583-590. [PubMed]

39. Nelson, J.O.; Watase, G.J.; Warsinger-Pepe, N.; Yamashita, Y.M. Mechanisms of rDNA Copy Number Maintenance. Trends Genet. 2019, 35, 734-742. [CrossRef] [PubMed]

40. Elder, J.F.; Turner, B.J. Concerted evolution of repetitive DNA sequences in Eukaryotes. Q. Rev. Biol. 1995, 70, 297-320. [CrossRef] [PubMed]

41. Wei, X.X.; Wang, X.Q.; Hong, D.Y. Marked intragenomic heterogeneity and gographical differentiation of nrDNA ITS in Larix potaninii (Pinaceae). J. Mol. Evol. 2003, 57, 623-635. [CrossRef]

42. Won, H.; Renner, S.S. The internal transcribed spacer of nuclear ribosomal DNA in the gymnosperm Gnetum. Mol. Phylogenet. Evol. 2005, 36, 581-597. [CrossRef]

43. Muir, G.; Fleming, C.C.; Schlötterer, C. Three divergent rDNA clusters predate the species divergence in Quercus petraea (Matt.) Liebl. and Quercus robur L. Mol. Biol. Evol. 2001, 18, 112-119. [CrossRef]

44. Wei, X.X.; Wang, X.Q. Recolonization and radiation in Larix (Pinaceae): Evidence from nuclear ribosomal DNA paralogues. Mol. Ecol. 2004, 13, 3115-3123. [CrossRef]

45. Colonna, V.; D’Agostino, N.; Garrison, E.; Albrechtsen, A.; Meisner, J.; Facchiano, A.; Cardi, T.; Tripodi, P. Genomic diversity and novel genome-wide association with fruit morphology in Capsicum, from 746k polymorphic sites. Sci. Rep. 2019, 9, 10067. [CrossRef]

46. Csilléry, G. Pepper taxonomy and the botanical description of the species. Acta. Agron. Hung. 2006, 54, 151-166. [CrossRef]

47. Carvalho, S.; Ragassi, C.; Bianchetti, L.; Reifschneider, F.; Buso, G.; Faleiro, F. Morphological and genetic relationships between wild and domesticated forms of peppers (Capsicum frutescens L. and C. chinense Jacquin). Genet. Mol. Res. 2014, 13, 7447-7464. [CrossRef] [PubMed]

48. Heiser, C.B.; Smith, P.G. New species of Capsicum from South America. Brittonia 1958, 10, 194-201. [CrossRef]

49. Datta, S.; Das, L. Characterization and genetic variability analysis in Capsicum annuum L. germplasm. SAARC J. Agric. 2014, 11, 91-103. [CrossRef]

Publisher's Note: MDPI stays neutral with regard to jurisdictional claims in published maps and institutional affiliations.

(C) 2020 by the authors. Licensee MDPI, Basel, Switzerland. This article is an open access article distributed under the terms and conditions of the Creative Commons Attribution (CC BY) license (http://creativecommons.org/licenses/by/4.0/). 